\title{
Environmental energetic model for the Energy industry in Spain
}

\author{
M.A.Verdejo ${ }^{1}$, J.R. Saenz ${ }^{2}$, J. Fernández ${ }^{1}$,M.Duran ${ }^{3}$ \\ ${ }^{1}$ Electrical Engineering Department \\ E.P.S. of Linares, University of Jaén \\ C/Alfonso X El Sabio, 28. 23700 Linares-Jaén (Spain) \\ Phone number: +34 953648582, email: mverdejo@ujaen.es, jmoreno@ujaen.es \\ 2 Electrical Engineering Department \\ E.S.I., University of Cadiz \\ C/Chile, 1. 11002 Cadiz (Spain) \\ Phone number: +34 956015140, email: jrsaenz@uca.es \\ ${ }^{3}$ Electrical Engineering Department \\ University of Málaga (University Campus El Ejido) \\ Plaza El Ejido, s/n. 29071 Málaga (Spain) \\ Phone number: +34 951952360, email: mjduran@uma.es
}

\begin{abstract}
Obtaining energy generation systems to fulfill the high energy demand allowing a sustainable development and maintaining the standard of life is one of the main aims of the energy policies in Spain and the European Union.

This work proposes a model which relates the different variables that influence the emissions and the environmental impact. This allows predicting the political implications which are dependent on the undertaken variables.
\end{abstract}

\section{Key Words}

Environmental engineering, environmental technology, $\mathrm{CO}_{2}$ emissions.

\section{Introducción}

The present situation in the energy sector, the limitation of resources and the environmental pollution has pushed researchers to actively work on this field.

This paper analyses the energetic situation in Spain, considering the planning and strategy for a sustainable energy system, both in the economic and environmental aspects, which can be realistically carried out in spite of the worldwide crisis. For this purpose it is necessary to develop both energetic and economic forecasting models to provide valuable data for the mid-term and long-term prediction. This work evaluates the period from 2005 to 2030.

According to the national plan of emission rights assignation, en the period 2008-2012, the emissions should be below $24 \%$ of the emissions in 1990 . This value is obtained adding the limitation aim of the Kioto protocol $(+15 \%)$, the estimation of drain absorption (max $2 \%$ ) and the credits that will be obtained in the international market (7\%). These data provide a realistic picture of the Spanish future unless more restrictive and efficient measurements are applied in order to decrease the $\mathrm{CO} 2$ emissions.

The most influencing parameters considered in order to establish the forecasting model are: absorption and CO2 emissions, forest biomass, demand and intensity of primary energy, energy vectors (coal, fuel, gas, hydraulic energy, nuclear energy and renewable energies), gross national product and taxes and energetic vectors for each variable in the period under study.

\section{Model}

The development of an environmental energy model for the Spanish industry is complex because of the combination of variables involved in the process and the difficulty in obtaining reliable data for the beginning of the period.

The achievement of the proposed goals requires a tool that combines the appropriate variables and implements the proposed mathematical model in order to obtain the future energy trends, as well s the evolution of the $\mathrm{CO} 2$ emissions. 
In the definition of the proposed model some assumptions have been made. The most relevant ones are listed below:

- The prescriptions in the White Book of the energy in Spain for the creation of an energy model and the Green Book of the European strategy for a sustainable, competitive and secure energy.

- The rate of growth used for the starting of the trend model has been taken from the statistical data since1995. However, in order to decrease the uncertainty, the model includes a weighting factor that allows the variation of these rates.

- The main scenario under consideration offers results up to 2030 and it will be the reference and basis of comparison for other alternative scenarios.

Table 1. Evolution of the main model variables.

\begin{tabular}{|c|c|c|c|c|c|c|}
\hline & \multicolumn{3}{|c|}{ Trend scenario } & \multicolumn{3}{|c|}{ Efficiency scenario } \\
\hline & 2004 & 2012 & 2030 & 2004 & 2012 & 2030 \\
\hline GNP $\left(10^{9} €\right)$ & 585 & 728 & 1176 & 585 & 728 & 1176 \\
\hline $\begin{array}{l}\text { Energetic } \\
\text { intensity } \\
\left(\mathrm{Ktep} / 10^{9} €\right)\end{array}$ & 236 & 244 & 263 & 236 & 222 & 220 \\
\hline $\begin{array}{l}\text { Energy } \\
\text { demand } \\
\left(10^{3} \text { Ktep }\right)\end{array}$ & 138 & 177 & 308 & 138 & 162 & 261 \\
\hline $\begin{array}{l}\text { Fossil fuels } \\
\text { demand }\end{array}$ & $\begin{array}{c}113,6 \\
82 \%\end{array}$ & $\begin{array}{c}141,8 \\
80 \%\end{array}$ & $\begin{array}{l}235,5 \\
76,5 \%\end{array}$ & $\begin{array}{l}113,6 \\
82,2 \%\end{array}$ & $\begin{array}{c}130,6 \\
81 \%\end{array}$ & $\begin{array}{c}198,5 \\
76 \%\end{array}$ \\
\hline Coal $^{*}$ & $14,8 \%$ & $17,88 \%$ & $17,46 \%$ & $14,8 \%$ & $14 \%$ & $11 \%$ \\
\hline $\mathrm{Oil}^{*}$ & $50 \%$ & $58,98 \%$ & $54,52 \%$ & $50 \%$ & $45,7 \%$ & $35 \%$ \\
\hline Gas $^{*}$ & $17,4 \%$ & $23,14 \%$ & $28,02 \%$ & $17,4 \%$ & $21 \%$ & $30 \%$ \\
\hline $\begin{array}{l}\text { Other fuels } \\
\text { demand }\end{array}$ & \begin{tabular}{|c|}
24,4 \\
$17,8 \%$
\end{tabular} & $\begin{array}{l}35,2 \\
20 \%\end{array}$ & $\begin{array}{c}72,5 \\
23,5 \%\end{array}$ & \begin{tabular}{|c|}
24,4 \\
$17,8 \%$
\end{tabular} & $\begin{array}{l}31,4 \\
19 \%\end{array}$ & $\begin{array}{l}62,5 \\
24 \%\end{array}$ \\
\hline Hydraulic $^{*}$ & $1,9 \%$ & $2,1 \%$ & $3 \%$ & $1,9 \%$ & $2,1 \%$ & $2,5 \%$ \\
\hline Nuclear ${ }^{*}$ & $11,7 \%$ & $12 \%$ & $11 \%$ & $11,7 \%$ & $11 \%$ & $10 \%$ \\
\hline $\begin{array}{l}\text { Other } \\
\text { Renewable } \\
\text { Energies }^{*}\end{array}$ & $4,2 \%$ & $5,8 \%$ & $8,5 \%$ & $4,2 \%$ & $5,8 \%$ & $11,4 \%$ \\
\hline $\begin{array}{l}\text { Gross } \mathrm{CO}_{2} \\
\text { Enissions } \\
\left(\mathrm{Mt} \mathrm{CO}_{2}\right)\end{array}$ & $\begin{array}{c}326 \\
+15 \%\end{array}$ & $\begin{array}{c}405 \\
+43 \%\end{array}$ & $\begin{array}{c}667 \\
+135 \% *\end{array}$ & $\begin{array}{r}326 \\
+15 \%{ }^{*}\end{array}$ & $\begin{array}{r}365 \\
+29 \%{ }^{*}\end{array}$ & $\begin{array}{c}560 \\
+98 \%\end{array}$ \\
\hline $\begin{array}{l}\text { Kioto } \\
\text { Emissions } \\
(+15 \%)\end{array}$ & 262 & 262 & 262 & 262 & 262 & 262 \\
\hline $\begin{array}{l}\text { PNA } \\
\text { Emissions } \\
(+24 \%) \\
\end{array}$ & 283 & 283 & 283 & 283 & 283 & 283 \\
\hline
\end{tabular}

* Increase percentage relative to the values of the National Plan of assignment

- The main results are the intensity of primary energy, the primary energetic demand, with and without fuel, the value of the absorptions and the $\mathrm{CO} 2$ emissions for different technologies, sources and countries.

In spite of the difficulty in correlating the considered variables and the limitations and restrictions due to the interaction of different type of data (economic, energetic and environmental), the model provides results close to the expectations, compared with other studies that use other model and forecasting plans.
There are many applications that can be carried out with the proponed model. It is just necessary to change any of the data involved in the model (energetic, economic or reference rate) to generate a new scenario.

The results confirm the accuracy of the model, both in the trend scenario and in the efficiency scenario. The results have been compared with other models (Table 1) whose quality is guaranteed by Spanish official organizations.

\subsection{Evaluation of the energy intensity according to the efficiency model.}

The variation of the energy intensity in 2004-2012 has a year rate of $(-0,9 \%)$ and will estabilize in 2013 maintaining its value until the end of 2030.In this way it can be decreased from the initial values of $236 \mathrm{Ktep} / 10^{9} €$ in 2004 to the $222,45 \mathrm{Ktep} / 10^{9} €$ values in 2030222,45 Ktep $/ 10^{9} €$ en 2030.

Figure 1 shows the evolution of the energy intensity in the trend scenario and the efficiency scenario.

\section{INTENSIDAD ENERGÉTICA (KTEP/mME).ESC. EFICIENCIA}

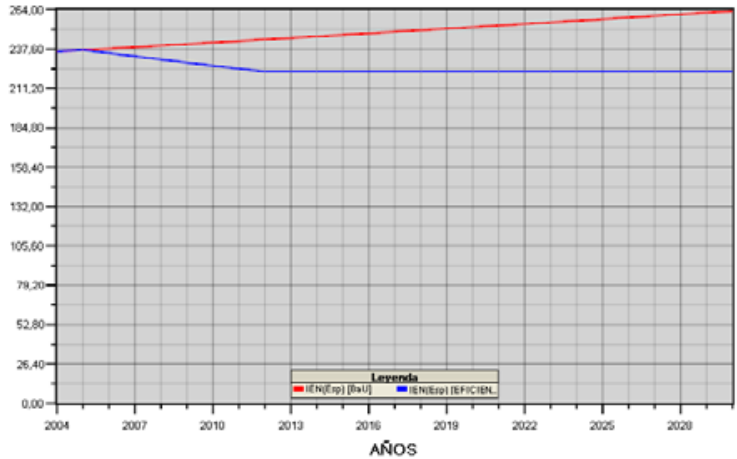

Fig.1: Energy Intensity (KTEP/Mm€)

This decreasing trend will generate a diminishment directly proportional to the primary energy demand, leading the country to evolve to a efficiency scenario which is similar to other countries in the UE-15. It can be observed in figure 2 how the increasing evolution of the energy demand has experienced a decrease with respect to the trend values.

\section{DEMANDA ENERGÉTICA (KTEP).ESC.EFICIENCIA}

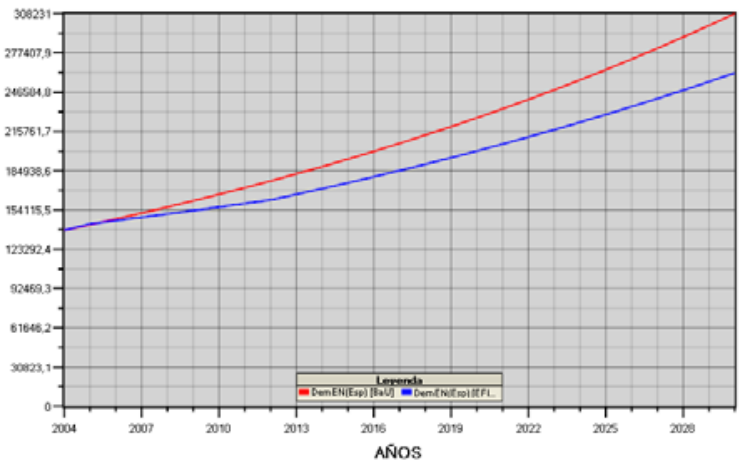

Fig.2: Energy demand (KTEP) 


\section{2. $\mathrm{CO}_{2}$ emissions in the efficiency model.}

Figure 3 shows the total emissions from the consumption of fossil fuels (EMs), the total emissions except from the absortions due to spanish forests (EMT) and the emissions established in the Kioto protocol as viable references to be followed. (EMKIOTO).

From the results shown in figure 3 it can be concluded that the growth within 26 years of the net emissions in Spain will be of $79 \%$ compared to 2004, 36 points less that the trend model-BAU, this indicating that 107 millions of tons of $\mathrm{CO}_{2}$ will stop from being thrown to the atmosphere.

COMPARATIVA EMISIONES CO2 (MtCO2)

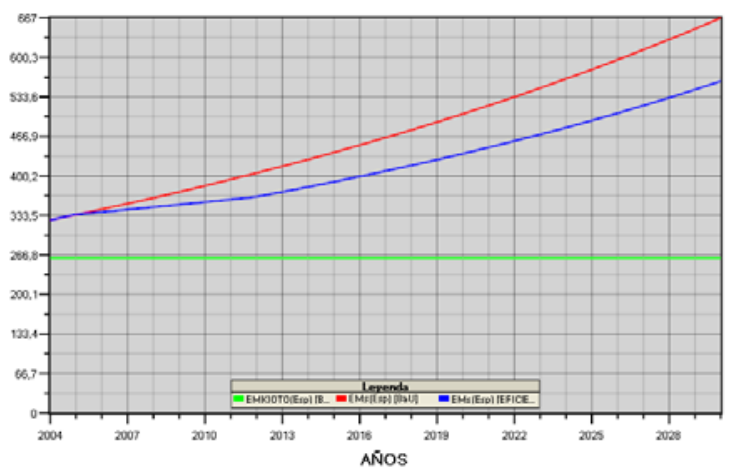

Fig. 3: $\mathrm{CO}_{2}$ emisions (Mt. $\mathrm{CO}_{2}$ )

In spite of being far from the levels demanded by the EU and the Kioto protocol (the growth compared to 1990 values are much higher than those established by the model), there is no doubt that avoiding the previously cited amount of emissions is valuable although not optimum.

The only solution to fulfill the current rules as far as emissions are concerned, is buying it from third countries, this being a policy followed in last years to achieve the levels established by international treatments.

\section{Comparative study with other analyses and acting plans.}

In order to validate the model and the obtained results, they have been compared to other reference analyses.

The proposed energy model has been implemented with the Globesight software which evaluates the measurements and current trends. This software has been used in other topics such as the human evolution.

The main studies usually reference to be compared with Globesight are that of the Marco agreement with the United Nations about the climate change in reference to Spain, the STERN report about the climate change applied to Spain, Estrategia de Ahorro y Eficiencia Energética en España (2004-2012), and the report World energy, technology and climate policy Outlook -WETO 2030).

These Studies and reports are carried out mainly a prediction horizon until 2010 and the WETO enlarges the horizon until 2030 but for he global EU, and consequently an exhaustive comparison is not possible.

The action plan 2005-2007 of the E4 proposes a save of primary energy in that period of 12.005 Ktep and the obtained results show a save of primary energy for the same period of 10.085 Ktep [5].

The renewable energies plan 2005-2010 proposes that the renewable energies, including the hydraulic from 10 to $50 \mathrm{MW}$, become a $12 \%$ of the total primary energy in 2010. In the obtained results in the efficiency model proposed in this paper, it is obtained a $7.5 \%$ of the renewable energies vector over the total demand of primary energy, being this data more real than the proposed in the PER. A 12\% is achieved in 2024 [4].

In the report of the Marco agreement with the United Nations about the climate change, two scenarios are proposed to predict the GEI emissions. A first scenario "with measurements", in which the aim is the save by 2020 the amount of $68.884 \mathrm{KT}$ of $\mathrm{CO}_{2}$ equivalent respect to the emissions in an scenario without measurements.

In the efficiency model that is proponed, a save of 70 millions of $\mathrm{T}$ de $\mathrm{CO}_{2}$ is obtained by 2020 . This value is very close to the predictions of the Marco agreement with the united nations.

\section{Conclusions}

It can be noted that following a trend based on the use of non renewable energies and on the use of fossil fuels, the $\mathrm{CO} 2$ emissions associated to the penalizations imposed by the EU related to the compliance with the Kioto protocol will imply a strong economical impact. To the contrary, if sustainable action plans start to be applied, those that plead for the save and the energetic efficiency and those that favour the use of renewable energies, there will be not only an economic profit in the mid and long term but also a strong environmental profit.

The evolution of the Sustainable Energy Model is carried out considering the increase of the natural gas as the main motor of the Spanish economy, increasing its participation vector from $17 \%$ to $30 \%$ in 2030 , so that the coal is decreased from $15 \%$ to $11 \%$ of the energy mix and the oil is also decreased from $50 \%$ to $34 \%$.

The GEI and mainly the CO2 emissions, which are 85\%, have with no doubt a high value and they are out of the Kioto commitment and the European agreements. 
It can be observed that the growth of renewable energies, applying the sustainability action plans, E4 and others, will grow until $1 \%$ of the energy mix in 2030 and until $24 \%$ if one includes the nuclear energy. This percentage is basic for the evolution of the efficiency in Spain, although not absolutely acceptable, since it proves to be insufficient to achieve a stable economic situation in the CO2 emissions market.

It can be clearly appreciated that the main factors influencing the energy evolution Spain, Energy intensity, GNP, Energy demand, CO2 emissions will show a growth in the considered period (2004-2030). Nevertheless, it must be highlighted that the present energy crisis will be an incident that will diminish this growth, although the increasing trend will continue after 2012 according to the latest studies.

This will happen in a trend and pessimistic scenario such as the efficiency scenario, with the application of the energy policies of the government imposed by the Kioto protocol and by the treatments and emission assignation rights in the European Union.

\section{References}

[1] Subdirección General de Planificación Energética. Ministerio de Industria, Turismo y Comercio. Evolución del consumo energético en España. 2005. Febrero 2006.

[2] Nieto, Santamaría. Evolución de las Emisiones de Gases de Efecto Invernadero en España. (1990-2006).

[3] Mech,A.Z.;Rouse,S. "Macro and Micro Economic Principles of the Kyoto Protocol Result". EIC Climate Change Technology, 2006 IEEE. May 2006

[4] Country analysis. The European environment. State and outlook 2005

[5] Ministerio de Industria, Turismo y Comercio. IDAE. Estrategia de ahorro y eficiencia energética en España, 2004-2012. E4. Plan de acción 2005-2007. Julio 2005.

[6] European Commission. World energy, technology and climate policy outlook. WETO 2030. Final report.

[7] Secretaría General de Energía. La energía en España. Madrid, 2004.
[8] Kockar, I. "European Union perspective on the Kyoto protocol: emissions trading scheme and renewable resources”. Power Engineering Society General Meeting, 2006. IEEE. June 2006

[9] Communication from the Commission to the council and the European Parliament. "The share of renewable energy in the EU”. Brussels, 26.5.2004.

[10] Secretaría del Cambio Climático. Convención Marco de las Naciones Unidas sobre el Cambio Climático. “Los diez primeros años”. Bonn (Alemania), 2004.

[11] J.I. Pérez Arriaga. Libro blanco sobre la refoma del marco regulatorio de la generación eléctrica en España. Madrid, junio 2005.

[12] Convenio Marco de las Naciones Unidas sobre el Cambio Climático. Instrumento de Ratificación del Protocolo de Kioto. Diciembre, 1997.

[13] Balance Energético 2006 y Perspectivas: El Sector del Petróleo. Dominique de Riberolles. Club Español de la Energía. Abril.2007.

[14] Working Group II Contribution to the Intergovernmental Panel on Climate Change Fourth Assessment Report. Climate Change 2007: Climate Change Impacts, Adaptation and Vulnerability.

[15] J.J. de Felipe Blanch., J. Xercavins i Valls. "Posibles escenarios futuros mundiales de emisiones y absorciones de CO2 y cumplimiento de los acuerdos de Kioto”. UPC. 2002. 